\title{
Future of Treatment of Temporomandibular Joint Dysfunctions in Parkinsonian Patients
}

\author{
Reda Ahmed Nofal1,2*, Alaa Abdelqader Altaweel ${ }^{3}$, Yasser Ibrahim Seada ${ }^{4}$ \\ ${ }^{1}$ Associate Professor of Oral and Maxillofacial Surgery, Faculty of Dentistry, Alazher University, Cairo, Egypt \\ ${ }^{2}$ Umm Al-Qura University (UQU), Mecca, Saudi Arabia \\ ${ }^{3}$ Lecturer of Oral and Maxillofacial Surgery, Faculty of Dentistry, Alazher University, Cairo, Egypt \\ ${ }^{4}$ Assistant Professor, Department of Physical Therapy, Cairo University, Giza, Egypt \\ Email ${ }^{*}$ redanofal11@yahoo.com
}

Received 4 March 2014; revised 7 April 2014; accepted 15 April 2014

Copyright (C) 2014 by authors and Scientific Research Publishing Inc.

This work is licensed under the Creative Commons Attribution International License (CC BY).

http//creativecommons.org/licenses/by/4.0/

(c) (i) Open Access

\section{Abstract}

The purpose of the study was designed to clarify the modern trends of physical therapy in treatment of temporomandibular joint dysfunctions in Parkinsonian patients, which in this respect included the degree of pain, the muscles power of both masseter and pterygoid, the range of TMJ motion, the angle of mouth opening and their effects on electromyography study in both sexes. Subjects: Thirty males and females were the same degree of disabilities according to modified Hoehn and Yahr scales (grade 3) of Parkinsonian patients, and their age ranged from 50 - 77 years old and their weight ranged from $60-88 \mathrm{~kg}$. They were randomly divided into two equal groups (G1 and G2). G1 (control) consisted of 15 patients of both sexes and was treated by exercises therapy program and G2 (experimental) consisted of 15 Parkinsonian patients of both sexes and was treated by the same exercises therapy program and low level pulsed electromagnetic therapy. Vital signs such as blood pressure, body temperature, pulse rate and respiratory rate were measured before and after the treatment sessions. Assessments: Visual analogue scale was used to measure degree of pain. Tensiometer was used to measure the muscle power of masseter and pterygoid, the digital goniometer was used to investigate the range of TMJ movement. Moreover, standard electromyography test (EMG) was used to measure the compound muscle action potentials. Statistically the results for all groups were analyzed by t-test to compare the differences between the two groups. The statistical package of social sciences (SPSS, version 10) was used for data processing using the P-value 0.05 as a level of significance. Results showed that there were significant improvements in all variables in G2 only. However, there was a little improvement but not significant in both G1. Therefore, it could be concluded that the use of low level pulsed electromagnetic therapy combined with exercises program was the good method to control pain of TMJ, increase of muscle power and the range of their movements together with determination of electromyography. Our results opened a new link to manage the TMJ dysfunctions in Parkinsonian patients via the use of low level pulsed electromagnetic therapy combined with exercises program.

\footnotetext{
"Corresponding author.
} 


\section{Keywords}

\section{Electromagnetic, Temporomandibular Joint, Parkinsonian Patients, Electromyography, Tensiometer, Goniometer, Pain and Range of Motion}

\section{Introduction}

Parkinson's disease is a chronic illness with major problems requiring personal and social adjustments. The incidence of Parkinson's disease is thought to be $1 \%$ of the general population, and has been estimated to reach $10 \%$ among the population of over 65 years of age. The progressive nature of Parkinson's disease often causes disruption in the daily function, roles and activities of the affected individuals [1].

Parkinson's disease is associated with a tendency to assume and maintain fixed postures. All aspects of movements are affected including initiation, alteration in direction and the ability to stop movement once it has begun. Also, spontaneous or associated movements as arm swinging in gait or smiling at a funny story are affected. Moreover, the orofacial functions are affected especially the temporomandibular joint movement [2].

The flexed postures of the head, neck lead to disorders of the Orofacial functions as TMJ range of motion, power of mastication and pain have been produced in Parkinson's disease by the ablation of the globus pallidus bilaterally [3].

Temporomandibular joint dysfunction (TMD) is very common and more than 10 million people in the United States have it. Jaw pain is one of the symptoms of TMD. It's important to know that jaw pain also can be a symptom of heart attack. Seek medical care immediately if jaw pain is accompanied by chest pain, shortness of breath, dizziness, left arm pain, numbness in left arm and nausea [4].

Bad posture habits in Parkinsonian patients are common reasons of TMD because of long time of flexion position of head and neck. Also, trismus (lockjaw), where the jaw muscles spasm (rigidity) and the jaw cannot be fully opened. Rigidity involves all muscle groups of the face, tongue and even those of the larynx are often affected [5].

Electromyography (EMG) can be used to assess amplitude and timing of onset of the supporting muscle group's activity in order to describe pattern of movement [6]. EMG can be useful to assess muscle activity during gait simultaneous and coordinated movement [7]. So, the EMG is used very effectively in evaluation of musculoskeletal disorders and neurological deficits [8].

Nowadays, the uses of pulsed low frequency electromagnetic as an adjuvant and supportive treatment in management of Parkinsonian cases are widely spread and of increasing interest, and they play an important role in controlling the Orofacial complication. Moreover, the electromagnetic therapy can delay or prevent the TMD and widely used in the hope to improve Orofacial dysfunctions [9].

The Kinesiological studies have significantly high-lighted the muscle function under both normal and pathological conditions. Electro-myography (EMG) is the most important method used in kinesiological and biomechanical studies, which is used to determine muscle function or to relate EMG output to developed tension. In addition, EMG technique may have the advantage of providing muscle specific motivation compared with a technique that is based entirely on mechanical measurements of force and endurance [10].

A relatively powerful magnetic field set up in large coil into which the part can be placed is provided by some machines. This field is oscillated, changing direction at various frequencies up to $50 \mathrm{~Hz}$. Other pulsed devices use higher pulsing frequencies but much weaker magnetic fields and are placed in contact with the part to be treated [11], which found that the field settings of a pulsed magnetic fields machine is specified as producing vasodilatation. There is good evidence of the effectiveness of low-frequency pulses applied to the tissues by electromagnetic induction in the treatment of un-united fractures [12] and Perthes' disease [13]. Similar $0.38 \mathrm{~m} / \mathrm{s}$ pulses at around $0.72 \mathrm{~Hz}$ have been used successfully in the treatment of rotator cuff tendinitis.

Numerous experiments demonstrated the low frequency effects of electric and magnetic fields on cells, tissues, organs, systems and even behavior in animals and humans. There is an evidence of their effects on the central nervous system, on fat and calcium metabolism and on circadian rhythm in humans and animals with various strengths and frequencies [14]. There is no certain evidence of significant health damage from artificial electromagnetic field [15]. 
A number of devices are available which generate pulses at a tiny fraction of the power. They produce pulses of $27.12 \mathrm{MHz}$ oscillations at various repeated rates but with power about $0.5 \mathrm{w}$ to peak $15 \mathrm{w}$. There are some reports of their effectiveness in treating variety of conditions as muscle spasm [16] and ligament sprains [17].

EMG has been used effectively in evaluating and following up most musculoskeletal and neurological disorders. EMG can be used to assess amplitude and onset of the supporting muscle group's activity in order to describe pattern of movement. Moreover, EMG is of great help in study muscle activity during gait with simultaneous and coordinated movement [5].

It is apparent that EMG activity of the muscles performing task before arrival of sensory feedback information from the muscles, joints and skin could modify the centrally generated movement program. These changes in neuronal activity occurred 50 to $200 \mathrm{~m} / \mathrm{sec}$ before EMG activity changes and there are enough overlaps of the onset of these changes [4].

Oedema and bruising were found to be less on the treated side during a controlled study of recovery after bilateral blepharopalsy [18]. All these sources apply energy for the tissues by means of an induction coil aerial placed on the surface of the skin. It has been claimed that the proximity of the tissues compensated for their low output, low-power pulses used successfully to encourage healing of skin wounds [19], applied low-power pulsed electro-magnetic energy via a cervical collar for persistent neck pain and found an increase in range of movement and a decrease in pain compromised if you have diabetes.

Therefore, new strategies with classic as well as new electromagnetic therapy should be implemented in the treatment of Parkinsonism.

In this respect, we design our study in trial to find out a synergistic effect between electromagnetic and regular exercises regime incorporating the muscles of TMJ to limit and control the rigid muscles complications of TMJ in Parkinsonian patients.

\section{Subjects, Material and Methods}

\subsection{Selection Criteria}

Parkinsonian patients were selected from the outpatient department Neurology and Neurological Rehabilitation. King Khalid Hospital, Najran University. Thirty patients diagnosed grade 3 according to modified Hoehn Yahr classification of disabilities. They were diagnosed on laboratory and clinical bases by their own specialists, their ages ranged from 50 - 77 years, they had the same degree of impairment, all patient's otherwise clinically and medically stable, they were otherwise medically fit to participate in the study according to procedure, they had sufficient cognition to understand the requirements of the study, they had no surgical interference. They had no signs of aphasia, they had sufficient vision and hearing, and the patients were randomly and equally divided into three groups. Group (1) Consisted of 15 patients of both sexes who received strengthening exercises of masseter and pterygoid, PNF technique for head and neck, lateral manipulation of TMJ and postural correction exercises of head and neck. Time of exercises 45 min, repetition10 times, stretching equal strengthening and rest inbetween, three times per week, day after day. Group (2) Consisted of 15 patients of both sexes who received pulsed low level electromagnetic therapy and the same exercises program. They were subjected to the following assessment: degree of disabilities, muscle tension (power) assessment, range of motion assessment, angle of TMJ opening, pain of TMJ and muscle activities.

\subsection{Inclusion Criteria}

Thirty Parkinsonian patients of both sexes, stage III according to modified Hoehn and Yahr classification of disabilities appendix. All patients were medically stable by measuring vital signs which include (blood pressure, temperature, pulse rate and respiratory rate) appendix. All patients were conscious and co-operative. All patients were medically, neurologically and psychologically normal. All patients had no disability secondary to orthopedic problems or surgery. All patients had no impairment of general or special senses. All patients were classified grade 3 according to modified ( $\mathrm{H} \& \mathrm{Y}$ ).

\subsection{Exclusion Criteria}

Severe degree of disabilities, Parkinsonian patients having complications, psychological unstable, non co-operative patients during assessment of the research and Persons having history of diabetes up to second degree rela- 
tions were excluded.

\subsection{Evaluation Procedures}

Patient's preparation: Before putting EMG electrodes over the skin for each patient, it should be shaving the hair at the picking areas and cleaning it by alcohol to remove the dead layers of the skin in site of EMG electrodes (masseter).

\subsection{Electrodes Testing Procedures}

Recording surface electrode was placed on the belly of a muscle. Ring electrode was placed on the proximal interphalangeal joint of the index or thumb for anti-dramic sensory studies. Ground electrode was placed on the level of wrist joint between stimulating and recording electrodes. Reference electrode was placed on distal interphalangeal joint. Then stimulate the mandibular branch of trigeminal nerve by stimulating electrode. The duration of the stimulation impulse was $0.2 \mathrm{~ms}$.

\subsection{Electrodiagnostic Test}

Technical steps of application EMG include electrode placement, skin temperature correction, and determination of nerve stimulation intensity and analysis of the evoked neuro-electrical response. The system comprises an electronic monitor and a report generation system. The registry stores all electrophysiological data including raw wave forms and limited demographic information (age, height, weight and gender). The EMG tests are typically performed by official clinical staffs that undergo training by the manufacture. The instrument and the data registry have automated quality assurance software that confirms and tracts ongoing staff competence. Each study is coded with the primary clinical indication for the evaluations.

\subsection{Instrumentation}

A-EMG Neuropac. B-Digital Goniometer. C-Lafayette Tensiometer. D-ASA Electromagnetic. E-Visual Analogue Scale.

\subsection{Electromyography (EMG) Unit}

It contains of EMG apparatus, Disposable surface EMG electrodes and Data processing computer unit, the Neuro Pack S1 MEC-9400K, 4 Channel EMG/EP System, Disposable and Radiolucent Electrodes.

\subsection{Electrodes}

Vitrode F Disposable Electrodes, G210DPart No. F-150M, Adult, solid tape, $25 \times 45$ mm, 3 pcs $\times 50$ packs/box. Vitrode V Disposable Electrodes, G272APart No. V-09OM3, Adult/Child, 3 lead, DIN, lead length, 1 m, $25 \times$ $45 \mathrm{~mm}, 3$ colors $\times 30$ packs/box.

The electrodes were self adhesive with active surface area of $1 \mathrm{~cm}^{2}$ in diameter. The electrodes consisted of plastic foam material with a silver plate disc on one side and silver plate snap in the center on the other side. Early released protective sheet was placed over the electrode side to keep the electrolyte part of the disc in its position. The electrodes were connected to EMG apparatus channel.

\subsection{Materials and Methods}

The study was carried out in King Khalid Hospital, Department of physical therapy and rehabilitation, Najran University. Thirty patients were diagnosed grade 3 according to modified Hoehn and Yahr of disabilities, their ages ranged from 50 - 77 years old and their weight ranged from 60 - $88 \mathrm{~kg}$. They were randomly divided into two equal groups (G1 and G2). G1 was treated by exercises therapy program only, the exercise training group performed training for 6 weeks (3 days/week, 45 min, 50\% - 80\% VO2 max) and G2 was treated by the same exercise program as G2 and pulsed low frequency electromagnetic therapy. Vital signs as blood pressure, body temperature, pulse rate and respiratory rate were measured before and after the treatment sessions. All patients were assessed by electromyography, Digital goniometer, Lafayette Tensiometer and Visual Analogue scale for measurement of TMJ dysfunctions. 
Detailed socio-demographic data, family history and medical history were taken from all the subjects and their physical and clinical examinations were done on very first day of the visit to physical therapy department. Informed consent was taken from each of the subjects. On the day of experiment, fasting blood glucose sample was collected and the nerve conduction study was carried out. Anthropometric measurements were taken before and after the treatment sessions, Neurological parameters of median nerve were measured by a standard EMG machine, were included according to the protocol recommended by San Antonio Conference on diabetic neuropathy action potential were measured by Electromyography (EMG) equipment. Range of motion of TMJ was measured by electronic goniometer (digital). Muscle power (tension) of masseter and pterygoid were measured by Tensiometer, Pain was measured by Visual analogue scale and degree of TMJ of disabilities was measured by modified unified Parkinsonian rating scales.

\subsection{Statistical Analysis}

The results of two groups were statistically analyzed by t-test to compare the differences within each group and between the two groups. The statistical package of social science (SPSS version 10) was used for data processing the P-value 0.05 level significance.

\subsection{Data Summarized by Using}

The arithmetic mean average describing the central tendency of observation where the standard deviation (SD) used to measure to described the results around mean where paired and unpaired t-test was performed to determine the significance difference pre and post within the same group and the differences between the two groups.

\section{Results}

\section{Subjects Characteristics}

Thirty males and females subjects participated in the study, their ages ranged between ( 50 - 77) years with mean age (56.4 \pm 6.6$)$ years, their weights ranged between (60 - 88) $\mathrm{kg}$ with mean weight $75 \mathrm{~kg} \pm 7.7 \mathrm{~kg}$. The subjects were divided into two equal groups. Each group consisted of fifteen subjects. The characteristics of subjects in each group are shown in Table 1 and Figure 1.

The independent $t$ test between the two groups showed no significant differences between groups or within groups of age (where P-value was 0.81) and weight (where P-value was 0.87), as shown in Table 1 and Figure 1 and Figure 2.

The results of the independent t-test between the two groups revealed that there were no significant differences in the Hoehn test measured before the experimental trial where the T-value was -0.38 , while $\mathrm{P}$ was 0.707 , and moderate significant differences when measured post experimental trial where the T-value was 3.95, while $\mathrm{P}$ was 0.001 as shown in Table 2 and Figure 3.

The results of the dependant t-test between pre and post test of group I revealed that there were mild significant differences in the Hoehn test where the T-value was 2.82, while $\mathrm{P}$ was 0.014 , and moderate significant differences between pre and post test of group II where the T-value was 10.46, while P was 0.001 as shown in Table 3 and Figure 3.

The results of the independent t-test between the two groups revealed that there were no significant differences in the hand function test measured before the experimental trial where the T-value was -0.414 , while $\mathrm{P}$ was 0.682 , and moderate significant differences when measured post experimental trial where the T-value was -8.78 , while P was 0.001as shown in Table 4 and Figure 4.

Table 1. Characteristics of subjects in each group.

\begin{tabular}{cccccccc}
\hline & \multicolumn{3}{c}{ Group 1 } & \multicolumn{2}{c}{ Group 2 } & P & Sig. \\
\cline { 2 - 5 } & Mean & SD & Mean & SD & & NS \\
Age (yrs) & 56.7 & \pm 6.3 & 56.1 & \pm 7.2 & 0.81 & NS \\
Weight $(\mathrm{kg})$ & 75.3 & \pm 6.8 & 74.8 & \pm 8.7 & 0.87 & . \\
\hline
\end{tabular}

P > 0.05: Indicates Non significance. NS: Non significance. 
Table 2. Results of the t-test between the two groups of Hoehn test measured before and after the experimental trial.

\begin{tabular}{|c|c|c|c|c|c|}
\hline & & Mean & SD & $\mathbf{T}$ & $\mathbf{P}$ \\
\hline \multirow{2}{*}{ Pre-test } & G I & 2.5 & \pm 0.5 & \multirow{2}{*}{-0.38} & \multirow{2}{*}{0.707} \\
\hline & GII & 2.5 & \pm 0.5 & & \\
\hline \multirow{2}{*}{ Post-test } & G I & 2.2 & \pm 0.5 & \multirow{2}{*}{3.95} & \multirow{2}{*}{$0.001^{* *}$} \\
\hline & GII & 1.7 & \pm 0.3 & & \\
\hline
\end{tabular}

Differences in Hoehn test within the two groups

Table 3. Results of the t-test within the two groups of Hoehn test measured before and after the experimental trial.

\begin{tabular}{cccccc} 
& & Mean & SD & T & P \\
\hline \multirow{2}{*}{ Group I } & Pre & 2.5 & \pm 0.5 & 2.82 & $0.014^{*}$ \\
& Post & 2.2 & \pm 0.5 & \pm 0.5 & 10.46 \\
\end{tabular}

Table 4. Results of the t-test between the two groups of muscle power test measured before and after the experimental trial.

\begin{tabular}{|c|c|c|c|c|c|}
\hline & & Mean & SD & $\mathbf{T}$ & $\mathbf{P}$ \\
\hline \multirow{2}{*}{ Pre-test } & G I & 8.7 & \pm 1.5 & \multirow{2}{*}{-0.414} & \multirow[b]{2}{*}{0.682} \\
\hline & GII & 8.9 & \pm 1.1 & & \\
\hline \multirow{2}{*}{ Post-test } & G I & 10.8 & \pm 1.6 & \multirow{2}{*}{-8.78} & \multirow{2}{*}{$0.001^{* *}$} \\
\hline & GII & 15.2 & \pm 1.1 & & \\
\hline
\end{tabular}

Differences in muscle power test within the two groups

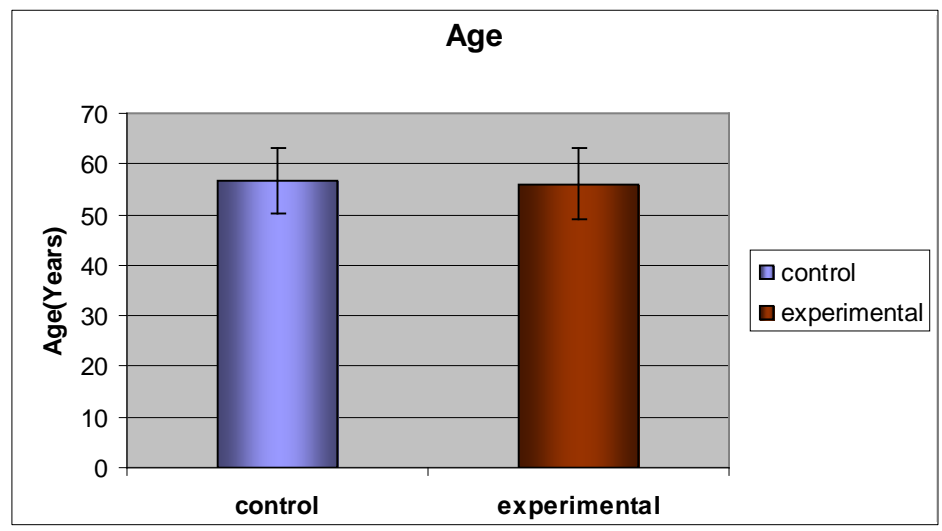

Figure 1. Showing the age characteristics of subjects in each group.

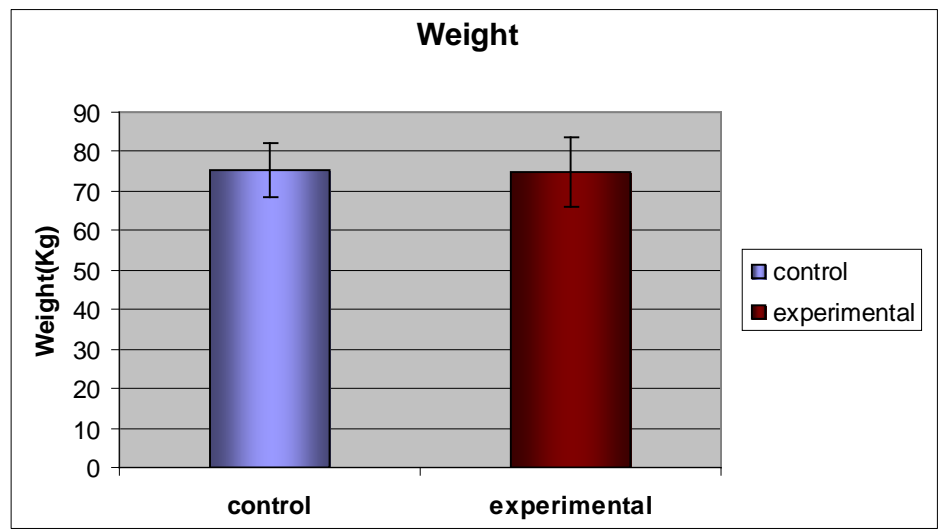

Differences in Hoehn test between the two groups

Figure 2. Showing the weight characteristics of subjects in each group. 


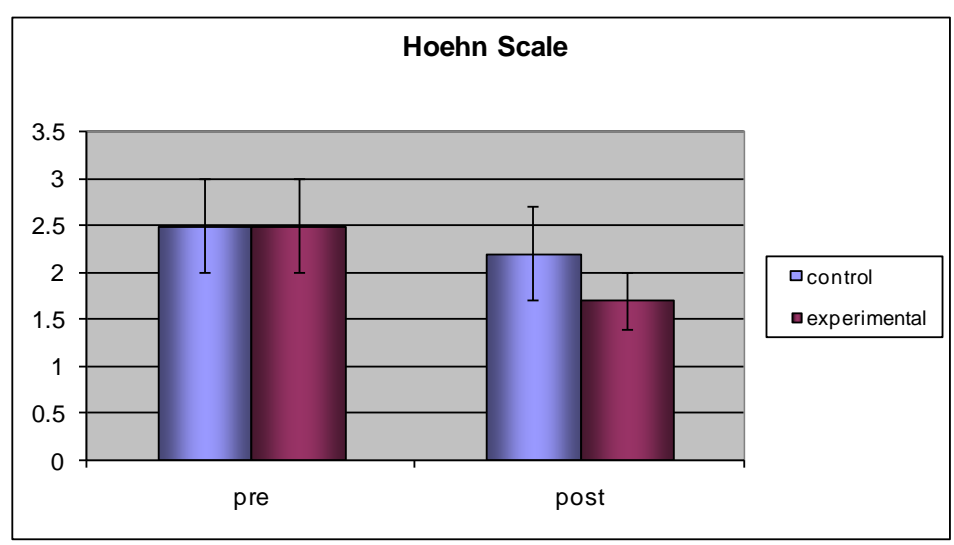

Differences in muscle power test between the two groups

Figure 3. Showing the results of Hoehn test in each group.



Differences in Range of motion between the two groups

Figure 4. Showing the results of muscle power test in each group.

The results of the dependant t-test between pre and post test of group I revealed that there were mild significant differences in Hand function test where the T-value was -12.91 , while $\mathrm{P}$ was 0.01 , and moderate significant differences between pre and post test of group II where the T-value was -23.44 , while $\mathrm{P}$ was 0.001 as shown in Table 5 and Figure 4.

The results of the independent T-value between the two groups revealed that there were no significant differences in the step length measured before the experimental trial where the T-value was 1.3 , while $\mathrm{P}$ was 0.96 , and moderate significant differences when measured post experimental trial where the T-value was -8.21 , while $P$ was 0.001 as shown in Table 6 and Figure 5.

The results of the dependant t-test between pre and post test for group I revealed that there were mild significant differences in step length where the T-value was -18.33 , while $\mathrm{P}$ was 0.01 , and moderate significant differences between pre and post test for group II where the T-value was -16.11 , while P was 0.001 as shown in Table 7 and Figure 5.

The results of the independent t-test between the two groups revealed that there were no significant differences in the foot angle measured before the experimental trial where the T-value was -0.542 , while $\mathrm{P}$ was 0.592 , and moderate significant differences when measured post experimental trial where the T-value was -15.944 , while $\mathrm{P}$ was 0.001 as shown in Table 8 and Figure 6.

The results of the dependant t-test between pre and post test of group I revealed that there were mild significant differences in foot angle where the T-value was -12.91 , while $\mathrm{P}$ was 0.01 , and moderate significant differences between pre and post test of group II where the T-value was -23.44 , while $\mathrm{P}$ was 0.001 as shown in Table 9 and Figure 6. 
The results of the independent t-test between the two groups revealed that there were no significant differences in the velocity of walking measured before the experimental trial where the T-value was 0.6 , while $\mathrm{P}$ was 0.97 , and moderate significant differences when measured post experimental trial where the T-value was -6.38 , while $\mathrm{P}$ was 0.001 as shown in Table 10 and Figure 7.

The results of the dependant t-test between pre and post test of group I revealed that there were mild significant differences in velocity of walking where the T-value was -9.51 , while $\mathrm{P}$ was 0.01 , and moderate significant differences between pre and post test of group II where the T-value was -14.4, while P was 0.001 as shown in Table 11 and Figure 7.

The results of the independent t-test between the two groups revealed that there were no significant differences in EMG for measured masseter muscles before the experimental trial where the T-value was -0.374 , while P was 0.711 , and moderate significant differences when measured post experimental trial where the T-value was -15.19 , while $\mathrm{P}$ was 0.002 as shown in Table 12 and Figure 8.

The results of the dependant t-test between pre and post test of group I revealed that there were mild significant differences in EMG of masseter muscle where the T-value was -15.9 while $\mathrm{P}$ was 0.01 and moderate significant differences between pre and post test of group II where the T-value was -29.79 , while $\mathrm{P}$ was 0.001 as shown in Table 13 and Figure 8.

The results of the independent t-test between the two groups revealed that there were no significant differences in EMG for pterygoid muscle measured before the experimental trial where the T-value was -0.132 , while $\mathrm{P}$ was 0.896 and moderate significant differences when measured post experimental trial where the T-value was -2.93 , while $\mathrm{P}$ was 0.007 as shown in Table 14 and Figure 9.

The results of the dependant t-test between pre and post test of group I revealed that there were mild significant differences in EMG of pterygoid muscle where the T-value was -13.26 while $\mathrm{P}$ was 0.01 and moderate significant differences between pre and post test of group II where the T-value was -20.58 , while P was 0.001 as shown in Table 15 and Figure 9.

Table 5. Results of the t-test within the two groups of muscle power test measured before and after the experimental trial.

\begin{tabular}{cccccc}
\hline & & Mean & SD & T & P \\
\hline \multirow{2}{*}{ Group I } & Pre & 8.7 & \pm 1.5 & -12.91 & $0.01^{*}$ \\
& Post & 10.8 & \pm 1.6 & & $0.001^{* *}$ \\
\hline \multirow{2}{*}{ Group II } & Pre & 8.9 & \pm 1.1 & -23.44 & \pm 1.1 \\
& Post & 15.2 & & \\
\hline
\end{tabular}

Table 6. Results of the t-test between the two groups of range of motion measured before and after the experimental trial.

\begin{tabular}{cccccc}
\hline & & Mean & SD & T & P \\
\hline \multirow{2}{*}{ Pre-test } & G I & 28.7 & \pm 1.1 & 1.3 & 0.96 \\
& GII & 27.4 & \pm 1.7 & & \\
Post-test & G I & 31.9 & \pm 1.8 & -8.21 & $0.001^{* *}$ \\
& GII & 36 & \pm 1.5 & & \\
\hline
\end{tabular}

Differences in range of motion within the two groups

Table 7. Results of the t-test within the two groups of range of motion measured before and after the experimental trial.

\begin{tabular}{cccccc} 
& & Mean & SD & T & \\
\hline \multirow{2}{*}{ Group I } & Pre & 28.7 & \pm 1.1 & -18.33 \\
& Post & 31.9 & \pm 1.8 & $\pm .01^{*}$ \\
Group II & Pre & 27.4 & \pm 1.7 & -16.11 & $0.001^{* *}$ \\
& Post & 36 & \pm 1.5 & \\
\hline
\end{tabular}


Table 8. Results of the t-test between the two groups of measured Angle of mouth opening before and after the experimental trial.

\begin{tabular}{cccccc}
\hline & & Mean & SD & T & P \\
\hline \multirow{2}{*}{ Pre-test } & G I & 4.3 & \pm 0.3 & -0.542 & 0.592 \\
& GII & 4.3 & \pm 0.3 & & 0.001 \\
\hline \multirow{2}{*}{ Post-test } & G I & 4.8 & \pm 0.4 & -15.944 & \pm 0.3 \\
& GII & 6.8 & & & \\
\hline
\end{tabular}

Differences in Angle of mouth opening within the two groups

Table 9. Results of the t-test within the two groups of angle of mouth opening measured before and after the experimental trial.

\begin{tabular}{cccccc}
\hline & & Mean & SD & T & P \\
\hline \multirow{2}{*}{ Group I } & Pre & 4.3 & \pm 0.3 & -12.91 & $0.01^{*}$ \\
& Post & 4.8 & \pm 0.4 & & $0.001^{* *}$ \\
\hline \multirow{2}{*}{ Group II } & Pre & 4.3 & \pm 0.3 & -23.44 & \pm 0.3 \\
& Post & 6.8 & & & \\
\hline
\end{tabular}

Table 10. Results of the t-test between the two groups of pain control measured before and after the experimental trial.

\begin{tabular}{cccccc}
\hline & & Mean & SD & T & P \\
\hline \multirow{3}{*}{ Pre-test } & G I & 38.64 & \pm 0.3 & 0.6 & 0.97 \\
& GII & 38.04 & \pm 0.3 & & $0.001^{* *}$ \\
\hline
\end{tabular}

Differences in pain control within the two groups

Table 11. Results of the t-test within the two groups of pain control measured before and after the experimental trial.

\begin{tabular}{cccccc}
\hline & & Mean & SD & T & P \\
\hline \multirow{2}{*}{ Group I } & Pre & 38.64 & \pm 0.3 & -9.51 & $0.01^{*}$ \\
& Post & 42.4 & \pm 0.4 & & $0.001^{* *}$ \\
\hline
\end{tabular}

Table 12. Results of the t-test between the two groups of EMG of masseter muscles measured before and after the experimental trial.

\begin{tabular}{cccccc}
\hline & & Mean & SD & T & P \\
\hline \multirow{3}{*}{ Pre-test } & G I & 0.6 & \pm 0.1 & -0.374 & 0.711 \\
& GII & 0.6 & \pm 0.1 & & 0.002 \\
\hline
\end{tabular}

Differences in EMG of Masseter muscles within the two groups

Table 13. Results of the t-test within the two groups of EMG of masseter muscles measured before and after the experimental trial.

\begin{tabular}{ccccrr}
\hline & & Mean & SD & T & P \\
\hline \multirow{2}{*}{ Group I } & Pre & 0.6 & \pm 0.1 & -15.9 & $0.01^{*}$ \\
& Post & 0.9 & \pm 0.1 & \pm 0.1 & -29.79 \\
\hline
\end{tabular}


Table 14. Results of the t-test between the two groups of EMG of pterygoid muscle measured before and after the experimental trial.

\begin{tabular}{cccccc}
\hline & & Mean & SD & T & \\
\hline \multirow{2}{*}{ Pre-test } & G I & 0.6 & \pm 0.1 & -0.132 \\
& GII & 0.6 & \pm 0.1 & \pm 0.896 \\
Post-test & G I & 0.9 & \pm 0.1 & -2.93 \\
& GII & 1.1 & $0.007^{* *}$ & \\
\hline
\end{tabular}

Differences in EMG of Pterygoid muscle within the two groups

Table 15. Results of the t-test within the two groups of EMG of pterygoid muscle measured before and after the experimental trial.

\begin{tabular}{cccccc}
\hline & & Mean & SD & T & \\
\hline \multirow{2}{*}{ Group I } & Pre & 0.6 & \pm 0.1 & -13.26 & $0.01^{*}$ \\
& Post & 0.9 & \pm 0.1 & \pm 0.1 & -20.58 \\
\hline
\end{tabular}



Differences in Angle of mouth opening between the two groups

Figure 5. Showing the results of range of motion in each group.



Differences in pain control between the two groups

Figure 6. Showing the results of angle of mouth opening in each group. 




Differences in EMG of masseter muscles between the two groups

Figure 7. Showing the results of pain control in each group.

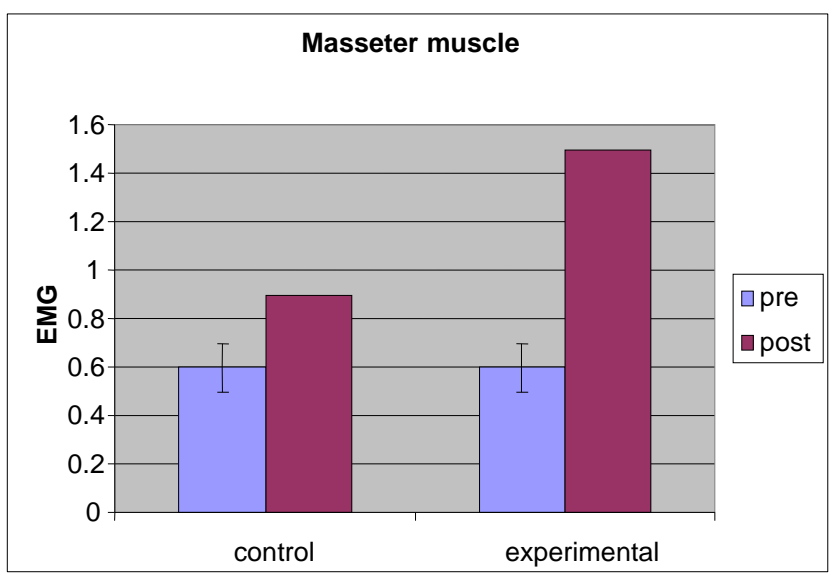

Differences in EMG of pterygoid between the two groups

Figure 8. Showing the results of EMG of masseter muscle time in each group.

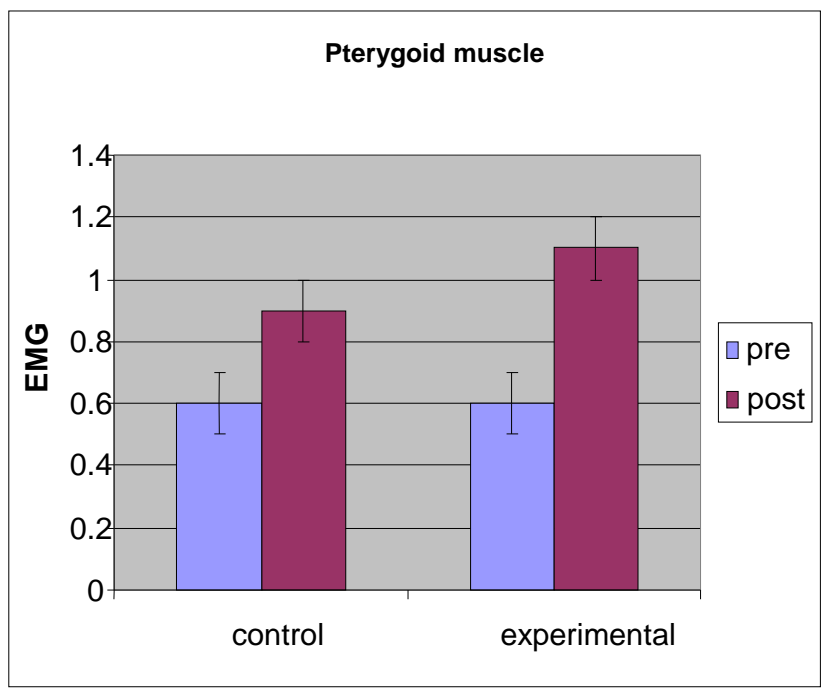

Figure 9. Showing The results of EMG of pterygoid muscle time in each group. 


\section{Discussion}

The purpose of this study is to investigate the effect of low frequency electromagnetic stimulation on electromyographic muscle activities (masseter and pterygoid), angle of mouth opening, range of motion of temporomandibular joint, and pain control in cases of Parkinsonian patients, referred to thirty Parkinsonian patients of both sexes (18 male and 12 female). Their ages during conducting this work were between 50 - 77 years. Vital signs were measured (blood pressure, temperature, pulse rate and respiratory rate) for all patients before, during and after the treatment sessions. Also, neurological assessment was done for all patients before conducting this work including speech, mental, sensory, motor, gait, hand function, tremor, rigidity, bradykinesia and coordination assessment.

In this study, the patients are assessed by a modified (H \& Y) staging of disabilities, unified Parkinson's disease rating scale, pain scale, digital goniometer, Tensiometer and EMG amplitude of different muscles (masseter and pterygoid) before and after the treatment program. Thirty Parkinsonian patients are randomly divided into two equal groups (GI and GII). GI received the traditional physical therapy program and GII received the same physical therapy program and low frequency electromagnetic stimulation. The statistics showed that there was a mild improvement in GI after the treatment program while there was a significant improvement in GII after the treatment program.

Although, there have been several recent clinical studies showing the positive effect of low frequency electromagnetic stimulation on Parkinsonian patients, such treatment hasn't been widely used in clinical setting yet. Several studies have demonstrated effects superior to those obtained by neurodevelopment therapy intervention [20].

Our study showed that there was a strong relationship between the application of low frequency magnetic field and the improvement of TMD parameter, where was moderate significant difference in muscle power, range of motion and angle of mouth opening. These results were confirmed by those obtained by [21] who applied the electromagnetic stimulation (TMS) with $0.2 \mathrm{~Hz}$ on two idiopathic Parkinsonian patients suffering from gait disorders and there was a mild improvement in stride width and posture during gait.

Our assessment in this study revealed that, the flexion attitude in Parkinson's disease has the ability to cause frequent TMD, tremor, rigidity, bradykinesia, cardiorespiratory affection, kyphosis, loss of balance, narrow base of support and loss of postural reaction. Some of these changes related to dose of L-dopa and the most didn't respond to any drugs, so this study scope on some important tasks of daily activities, gait and muscle activities [22].

Also, our EMG amplitude assessment of certain muscles activities during mouth opening (masseter and pterygoid) revealed that there was small amplitude where the mean was $(0.8-0.9 \mathrm{mV})$, this results are in agreement [23] when tibialis anterior muscle (TA) with amplitude was assessed $(0.8 \mathrm{mV})$ and gastrocnemus muscle (GC) with amplitude $(0.9 \mathrm{mV})$ on 30 Parkinsonian patients suffering from frequent falling. The patients were assessed by EMG during walking before the treatment program which included gait training, balance exercises and weight bearing exercises. The program of treatment continued for 8 weeks, each session $30 \mathrm{~min}$, day after day. Finally, the patients were assessed again. The statistics showed that there was a mild but not significant improvement in muscle amplitude as it had become in TA $(0.9 \mathrm{mV})$ and in GC $(1.3 \mathrm{mV})$.

Also, our study is in agreement with [24] using UPDRS to assess muscle power, range of motion and angle of mouth opening in 50 idiopathic Parkinsonian patients and 30 atherosclerotic Parkinsonian patients. They have suffered from frequent falling, freezing and tremor. In addition, [25] used UPDRS in 39 Parkinsonian patients to assess bradykinesia, rigidity, depression and balance. Also, [26] used UPDRS in 16 Parkinsonian patients to assess hand function and ADL.

This study is accordance with [27] when they assessed co-ordination in 21 Parkinsonian patients stage II and III according to H \& Y. They mentioned that the complex co-ordination of leg and arm swing during walking was one of the main output features of the central nervous system. Moreover, many neurological impairments affected the brain interfere with co-ordination of movements especially during gait function. Poor timing of toeoff, heel strike and weight shifting as well as bilateral symmetry exposed was based on experimental evidence.

In our study, we agree with other authors who mentioned that the Orofacial function in Parkinsonian patients has some typical features in the mechanism of TMJ disturbance but differs individually according to the extent and location of cerebral damage. After the assessment of different Orofacial parameters by EMG methods in 49 vascular Parkinsonian patients, they found that there was muscle spasm, decrease TMJ range of motion and limitation of mouth opening. They related these changes to the contractures of the muscles, rigidity, delayed reac- 
tion time, bradykinesia and freezing. Numerous balance studies had shown that in 20 post encephalitic cases the transfer and rotation activities markedly decreased during walking. The flexion attitude was also a common symptom affecting balance, posture and gait. Such deficits lead to short step length, prolonged step time, insufficient hip, knee and ankle excursion, frequent falling and increase energy consumption [28].

The present study is in accordance with [29] who concluded that TMS $0.4 \mathrm{~Hz}$ with a physical therapy program seemed to address the most of Parkinsonian patients' problems as function of ADL and also had the ability to improve many of gait disorders, balance, shuffling, falling and narrow base of support.

The external application of low frequency EMS could alter the cerebral excitability, brain rhythms, circadian rhythmicity and variety of behaviors in humans [30]. One mechanism which had received wide experimental support evaluated the effect of EMFS on calcium flux patterns [31]. Some of the most important calcium processes such as resting membrane potential, synaptic neurotransmitter synthesis and compound action muscle potential which were essential for the functioning of the neuron are influenced by electromagnetic facilitations (EMFs) [32]. In addition, the amplification via calcium flux could also provide the means by which the membrane mediates effects of EMFs on intracellular biochemical process [33].

Pulsed applications of EMFs at a specific range of frequencies, intensities and wave forms corresponding to the magnetic window of neural activity may alter calcium channel functions and thus increase the synthesis and synaptic release of neurotransmitter. In addition, pulsed EMFs may affect transmembrane calcium oscillations and thus alter resting membrane potential and neural excitability [34].

Moreover, [35] reported that the external application of EMFs affects neuroendocrine systems specifically the circadian rhythms of melatonin secretions from the pineal gland. Melatonin receptors have been demonstrated in the striatum and brainstem reticular formation [36]. The effect of TMS on the secretion of melatonin was relevant to the pathogenesis of Parkinson's disease since melatonin secretion had been diminished in patients with the disease [37] and also because melatonin regulate midbrain and limbic dopaminergic activity [38] as well as noradrenergic and serotonergic activity [39].

Melatonin was recognized to exert potent neuroprotective effects by inhibiting oxidative stress and neural damage. Also, melatonin increases messenger deoxyriboneuclic acid (m RNA) levels of the antioxidant enzymes manganese and increases the activity of glutathione peroxidase [40] [41]. Melanin is the most powerful endogenous antioxidant hormone [42]. Dopaminergic neurons are particularly susceptible to oxidative stress [43].

Recent studies on Parkinsonian patients suggested that the dopaminergic neurons were in a state of oxidative stress as evidenced by increased cellular iron accumulation, decreased glutathione levels and damage of neurons molecules including lipids, protein and deoxyneuclic acid (DNA) [44]. This oxidative stress was believed to facilitate the degeneration of striate dopamine neurons in Parkinson's disease and limited their ability to synthesis, store and release of dopamine. Augmentation production by intermittent TMS diminished oxidative stress, enhance neural activity and slow the rate of degeneration of dopamine neurons in PD [45].

Our study is supported by [46] who used EMS with $2 \mathrm{~Hz}$ on 9 Parkinsonian patients suffering from muscle weakness of TMJ. The patients were assessed by dynamic EMG changes where the mean amplitude of T.A was $0.8 \mathrm{mV}$ and GC was $0.9 \mathrm{mV}$ before the treatment. These the patients were treated by TMS that were $0.7 \mathrm{~Hz}, 20$ min, each session, day after day for 6 weeks. After that, the patients were reassessed, and there was improvement in EMG amplitude as T.A $1.0 \mathrm{mV}$ and GC $1.3 \mathrm{mV}$. Also, [47] mentioned that after 3 months of treatment by TMS $0.5 \mathrm{~Hz}$ in pilot study on 3 post encephalitic male patients suffering from limited trunk mobility, there was a significant improvement in trunk mobility measured by shuppered test and electronic goniometer of lumbar region. Moreover [48] stated that the application of TMS for at least 2 months on 16 idiopathic PD leads to increase the release of dopamine in striatum and improve most of symptoms.

The low frequency EMS $0.2 \mathrm{~Hz}$ in a experimental studies was applied on 70 idiopathic Parkinsonian patients divided into 7 groups, for 3 months, the patients were assessed by analysis of blood sampling for certain enzymes and by brain mapping. After the end of treatment by EMS, they concluded that there was an increase in apomorphine neurotransmitter enzymes and increase in the concentration of dopamine in striatum. Also, the long lasting treatment with TMS in PD was useful not only in depression but also in the treatment of hypokinesia, rigidity and tremor. So the TMS was considered the most appropriate method to be introduced as an effective therapeutic modalities in the treatment of PD [49].

This present study is in agreement with [50] who applied EMS on 12 idiopathic Parkinsonian patients suffering from rigidity. The treatment continued for 2 months with $0.5 \mathrm{~Hz}$ for $20 \mathrm{~min}$, the patients were assessed by timing of certain activities as changing position from sitting to standing and walking for $5 \mathrm{~m}$. After the treatment, 
the patients were assessed again. The statistics showed that there was a significant improvement in all activities.

After the researches were applied on more than 49 vascular parkinsonian patients manifested by impaired memory and cognition, [51] applied EMS $0.3 \mathrm{~Hz}$ for 3 months, day after day. The patients assessed by measured position emission tomography and brain angiography. He concluded that after the treatment program, the cerebral blood flow had been increased to the premotor cortical areas and to the striatum TMS activates the cortical motor area by antidromic facilitation to the corticospinal tract through the current flow to the internal capsule or transynaptic flow via the striatum.

Moreover, [52] found that EMS elicits the motor evoked potential response in the contralateral extremities after stimulation to each frontal cortex, excitation of the frontal cortical regions including motor, premotor and supplementary areas. Hence [53] reported that EMS not only activates the cortex via the corticospinal tract in PD but also activates transynaptically upon dysfunctional basal ganglia circuits via the striatum.

Recently, on the other ways, EMS $0.2 \mathrm{~Hz}$ successively 3 times per week for 4 weeks on 12 idiopathic Parkinsonian patients, they were divided into two equal groups. GI received rTMS to bilateral frontal cortex and GII received rTMS to bilateral occipital cortex. The regional cerebral blood flow was assessed by single photon emission computed tomography (SPECT), brain mapping and by clinical tests H \& Y to assess ADL activities as grade III before and after the treatment program. There was a significant improvement in GI through increasing cerebral blood flow than before, while in GII there were no significant changes. Also, there were significant improvements in $\mathrm{H} \& \mathrm{Y}$ which became grade II in GI, while there was no improvement in GII. Finally, who suggested that successive $0.2 \mathrm{~Hz}$ rTMS has out lasting inhibitory effect on neural discharges around the stimulated cortical areas [54].

In this experimental, study the analysis of mean values before and after the treatment program by tensiometer showed that there was a significant difference between the two groups with the best results for GII, this meant that EMS $0.5 \mathrm{~Hz}, 30 \%$ intensity and 20 min duration gave the best results in UPDRS. The prognosis may be a result of optimal learning of multimuscular coordination and correct hand function training by Purdue Pegboard according to explanation of [55].

In our study, we used $0.5 \mathrm{~Hz}$ EMS similar to work done by [56] where the results were the same but different in the frequencies of stimulation $2 \mathrm{~Hz}$. They proved that was an improvement in both slowness of walking and decreased arm swings. Also, these results were supported and confirmed by [57] when the extracted EMS 0.5 $\mathrm{Hz}$ was useful and effective in the treatment of 10 atherosclerotic cases of PD for 2 months, day after day. EMS coincides with balance training producing an appropriate pattern of gait through improving the integration of descending motor drive which consequently improves gait dynamics including initiation and stopping of movement.

In this study, $0.5 \mathrm{~Hz}$ was chosen in accordance with many studies, while [58] was applied $10 \mathrm{~Hz}$ in another study of EMS $10 \mathrm{~Hz}$ on parkinsonian subjects for 6 weeks. The results showed that, there was defect in walking pattern of many patients and the patients were unable to walk at their normal comfortable speed. While [40] showed that the result of this experimental study of low frequency of EMS than $10 \mathrm{~Hz}$ were more effective and [17] confirmed that the higher levels more than that $5 \mathrm{~Hz}$ can affect the gait pattern in an undesired manner. So, [59] chose $0.5 \mathrm{~Hz}$, the most suitable frequencies in the treatment of Parkinsonian patients.

The results of this study confirmed by the work of [60] who applied EMS on 9 atherosclerotic Parkinsonian patients, treated by TMS $0.3 \mathrm{~Hz}$ but differed in intensity (10\%) and less in duration (10 min). The results showed that there was a definite improvement in gait parameter and decrease reaction time when patients were reassessed by UPDRS.

The findings of this experimental study are closely agreement and supported by the findings of [61] who applied EMS with different frequencies $0.5 \mathrm{~Hz}, 5 \mathrm{~Hz}$ and $10 \mathrm{~Hz}$ on 30 idiopathic Parkinsonian patients. They were divided into 3 equal groups according to degree of disabilities of $\mathrm{H} \& \mathrm{Y}$. The treatment program was applied for 2 months, 3 sessions per week, 30\% intensities and $20 \mathrm{~min}$ in duration. GI was treated by $0.5 \mathrm{~Hz}$, GII by $5 \mathrm{~Hz}$ and GIII by $10 \mathrm{~Hz}$. finally the results showed that there were moderate significant differences in GI, mild improvements in GII and no improvements in GI. So, they concluded that the higher frequencies of TMS were more than $5 \mathrm{~Hz}, 30 \%$ intensities and 20 min hadn't any effect on gait pattern.

The statistical findings of this work were supported by [58] when they conducted a case report on idiopathic female Parkinson's disease. She had suffered from frequent falling during gait. The gait training for this patient required a continuous help from the therapist to assist the balance and prevent frequent falling. She received an additional therapy by EMS $0.3 \mathrm{~Hz}, 3$ times per week, 20 min for 6 weeks. Her gait ability was assessed every 
two weeks by UPDRS. At the end of the second week, she required only an intermittent help instead of a firm continuous support. After four weeks, she required a minimal help and after the six weeks she required only a verbal support and the patient was able to walk independently on the ground. Three months after the end of the study, the patient was still walking independently.

Our results are in agreement with the findings of [10] when they applied a study on 30 idiopathic Parkinsonian patients, and the subjects have limited the range of motion in lower extremities, contractures of neck muscles and disturbance of balance. They were treated by EMS $0.9 \mathrm{~Hz}$ and a physical therapy program included range of motion exercises, mobility and flexibility exercises. The treatment was done for 12 weeks, 3 days per week (day after day), the patients were assessed by $\mathrm{H} \&$ Y grade 3 of disabilities and by digital goniometer. At the end of the treatment program, the results showed that there was a significant improvement in the range of motion but minimal improvement in balance.

Also, the results of this work are accepted by the work of [22] when they applied EMS $0.3 \mathrm{~Hz}$ on 9 postencephalitic Parkinsonian patients and assessed ROM of trunk by digital goniometer and ADL by H \& Y. The treatment program was applied for 10 weeks. The results showed that there was an improvement in ADL activities more than ROM in lumbar region. These results were supported by [44] when they examined the beneficial effects of EMS $0.4 \mathrm{~Hz}$ on 5 idiopathic male Parkinsonian patients. The main problems of patients were short stride length and lack of reciprocal arm motion during walking. They were treated for 8 weeks, day after day and they were assessed by $\mathrm{H} \& \mathrm{Y}$ as at stage 4 . Their statistics revealed that there were changes in walking pattern and $\mathrm{H}$ $\&$ Y had become stage 3.

In this study, we used the dynamic EMG to assess mean amplitude of certain muscles, and this is similar to the work of [9] who used EMG amplitude in the assessment of biceps brachii in 26 idiopathic Parkinsonian patients suffering from an impaired hand function. They were divided into two equal groups, GI Consists of 13 patients $0.8 \mathrm{mV}$ in amplitude and stage 3 in $\mathrm{H} \& \mathrm{Y}$, GII consisted of 13 patients $0.7 \mathrm{mV}$ in amplitude and stage 4 in $\mathrm{H} \& \mathrm{Y}$. The patients in GI were treated by anti-parkinsonian drugs while GII was treated by TMS $0.4 \mathrm{~Hz}$. The treatment program was applied for 2 months, 3 sessions every week. After the end of the treatment program, in GI although medications decreased the clinical symptoms of patients but statistically it wasn't significant, while in GII there was an observable improvement in EMG amplitude $(1.1 \mathrm{mV})$ and hand function stage 3 in $\mathrm{H}$ \& Y.

In contrast to our study, [62] applied a study on 15 male idiopathic PD who suffering from retropulsion during walking, to determine the effect of EMS $8 \mathrm{~Hz}$ with regular rehabilitation program, $\mathrm{H} \& \mathrm{Y}$ stages 3 , the treatment program continued for 2 weeks, daily sessions. Finally, they reported that, there wasn't any significant improvement.

Our Statistics showed that the amplitude of masseter muscles was significantly improved after EMS from (mean $0.8 \mathrm{mV}$ ) to (mean $1.3 \mathrm{mV}$ ), these result was confirmed by [63] who found changes in the mean amplitude of dynamic EMG after the application of EMS $0.6 \mathrm{~Hz}$ on 47 idiopathic Parkinsonian patients. They were assessed by the dynamic EMG where the mean amplitude changes of gastrocnemus muscle $(0.8 \mathrm{mV})$ and tibialis anterior muscle $(0.7 \mathrm{mV})$ before the treatment program. The treatment was applied by EMS $0.4 \mathrm{~Hz}$ for 2 months, sessions day after day. At the end of the treatment program, the patients were assessed again; the statistics revealed that there was a significant improvement in EMG mean amplitude of masseter muscles to $1.3 \mathrm{mV}$ and tibialis anterior muscle to $1.0 \mathrm{mV}$. Moreover, they reported that there were different changes in EMG as increased duration of motor evoked potential, increased number of phases and increased amplitude.

Besides that, our study showed that there was a significant increase in EMG mean amplitude of gluteus maximus muscle after EMS from $0.8 \mathrm{mV}$ to $1.4 \mathrm{mV}$, this is in agreement with [64] who applied four different EMS frequencies $(0.5 \mathrm{~Hz}, 1 \mathrm{~Hz}, 5 \mathrm{~Hz}$ and $10 \mathrm{~Hz}$ ) on four selected groups of Parkinsonian patients of the same degree of disabilities according to H \& Y stage 3 in ADL. The patients were treated by TMS for 20 min., day after day. They were assessed by EMG for activities of biceps brachii muscle mean amplitude $(0.7 \mathrm{mV})$ and triceps muscle mean amplitude $(0.8 \mathrm{mV})$ before the treatment program. The statistics after the treatment program showed that there were significant differences in mean biceps muscle amplitude $(1.4 \mathrm{mV})$ and stage II in H \& Y of GI otherwise in GII there was a mild improvement but no significant changes in GIII and GIV.

In our present study, the statistics revealed that, there was improvement in EMG mean amplitude of pterygoid muscles from $0.6 \mathrm{mV}$ to $1.1 \mathrm{mV}$. This result was supported by [2] who applied EMS $0.3 \mathrm{~Hz}$ on 29 idiopathic Parkinsonian patients. The treatment program was applied for 3 months, day after day. They have suffered from lack of bed activities when assessed by H \& Y stage III and EMG amplitude of external oblique muscle of trunk was $0.7 \mathrm{mV}$ before treatment program. Finally, the results concluded that there were significant changes in EMG 
amplitude $(1.3 \mathrm{mV})$ and a minimal improvement in bed activities. Also, [65] was concluded by analyzing the firing pattern of motor units on 32 Parkinsonian by the effect of TMS $0.5 \mathrm{~Hz}$, which increased the rate of firing pattern and increased in motor unit action potential.

On the other hand, the motor excitability of Parkinsonian patients (rigidity) was measured by F-wave response from abductor policies brevis muscle. The assessment showed that there was a small amplitude and short duration of EMG pattern during gait in comparison to the same age of normal subjects. The treatments were applied by EMS $0.2 \mathrm{~Hz}$ for 2 months, 3 sessions per week. At the end of the treatment program, the statistics showed that there was an improvement in F-wave amplitude and duration than before but it still less than normal subjects. They concluded that the spinal motoneuron excitability was enhanced in Parkinsonian patients than normal subjects, especially in more rigid cases and the F-wave amplitude was significantly correlated to the clinical evaluation of motor disability. So, the F-wave considered a useful approach to evaluate the rigidity [17].

In our study, the digital goniometer results of TMJ range of motion showed that there were significant differences between both groups with the best results in a favor of GII. These results were in agreement with [51] who used EMS $0.5 \mathrm{~Hz}$ on 20 progressive supranuclear palsy cases suffering from frequent falling postural instability and impaired tip prehension when were measured by $\mathrm{H} \& \mathrm{Y}$ as stage 4 before the treatment program while 0 being normal and 4 being sever. They were divided randomly into two equal groups; GI was treated by dopaminergic drugs as L-dopa, amantadine, selegiline and pergolide mesylate, while GII was treated by EMS $0.4 \mathrm{~Hz}$ for 3 months, 3 sessions per week. Finally, the results showed that there were significant differences between both groups with the best results in GII. Falling has been reduced from grade 4 to 3, postural instability has become grade 2 and tip prehension has become grade 3 . They concluded that TMS was a highly efficacy method in the treatment of PSP.

Our present study is greatly supported by the work of [40] who applied EMS on 60 atherosclerotic Parkinsonian patients suffering from narrow base of support (BOS), their ages ranged between 50 - 77 years, stage 3 according to $\mathrm{H} \& \mathrm{Y}$. They were divided into 3 groups, each group 20 patients, 3 sessions per week for 3 months. GI was treated by EMS $0.5 \mathrm{~Hz}$, GII was treated by $2 \mathrm{~Hz}$ and GIII was treated by $5 \mathrm{~Hz}$. The patients were assessed as the same degree of disability grade 3 . After the treatment program they were reassessed again. The statistics concluded that there was a significant improvement in GI, minimal improvement in GII while no changes in GIII.

In our work, there is improvement in angle of opening of TMJ in both groups with the best results for EMS group. This coincides with the work of [66] who applied EMS $0.3 \mathrm{~Hz}$ on 27 post encephalitic patients suffering from limited neck movement (flexion, extension and rotation) as measured by digital goniometer. They were divided into two equal groups, GI was a control group treated by traditional physical therapy program, while GII was an experimental group which received the same exercise program, TMS $0.3 \mathrm{~Hz}$ for 2 months, each session 20 min, day after day. After the treatment program, there were significant differences in TMS group as compared to non TMS group.

Our study showed that, there was a significant improvement within the two groups in cycle time with the best results in GII. These results were confirmed and supported by [53] who found the use of TMS considered an effective method of treatment although it hasn't been widely used in clinical settings yet. A relevant finding from a study was that a large majority $90 \%$ of their patients were able to complete 3 months treating by TMS with a significant decrease in cycle time.

Finally, in this experimental study the analysis of mean values before and after the treatment by EMS showed that there were significant differences within the two groups with the best results of GII. These results mean that EMS $0.5 \mathrm{~Hz}, 30 \%$ intensity and 20 min duration have given the best results according to EMG, UPDRS, Tensiometer, digital goniometer and pain scale. This prognosis may be a result of optimal application of EMS technique, suitable frequency, appropriate intensity and optimum duration.

\section{Summary}

The purpose of the study is to evaluate whether rhythmical low frequency electromagnetic stimulation can improve the gait disorders and activities of daily living in Parkinsonian patients. 30 male and female Parkinsonian patients were selected from outpatient clinic of King Khalid hospital and outpatient clinic of Neuromuscular and Neurosurgical Disorders, Najran University, their ages ranged from 50 to 77 years with the mean age of (56 \pm 6.6) years, who were participated in this study. Patients were randomly divided into two equal groups and each group consisted of 15 patients, GI was a control group and was treated by traditional physical therapy program 
(stretching exercises, strengthening exercises, PNF, gait training, weight bearing exercises and ADL) without magnetic stimulation and GII was an experimental group and was treated by low frequency electromagnetic stimulation and also the same previous traditional physical therapy program. All subjects have received their exercise training for $40 \mathrm{~min}$ (five minutes training and five minutes rest respectively), this means 20 minutes of training and 20 minutes of rest, three days per week, day after day for six weeks, magnetic stimulation with frequency $0.5 \mathrm{~Hz}, 30 \%$ of intensity and 20 min of duration.

Vital signs (blood pressure, temperature, pulse rate and respiratory rate) and neurological assessment for all patients were measured before and after the treatment sessions. All patients were assessed clinically by EMG, UPDRS, tensiometer, digital goniometer and pain scale.

The statistical results showed a significant difference between the two groups with the best results for GII, regarding to all clinical, kinematic and electromyographic parameters.

\section{Recommendations}

With the limitation of this study and from the obtained statistical results, further investigations and research studies are recommended. It is important to investigate the optimal period after the lesion during which to initiate the magnetic stimulation to maximize rhythmical gait training and hand function. Further studies should be attempted to describe the effect of magnetic stimulation on speech, cognition and facial expression. Also, studies should be attempted to describe the EMG activity of upper limbs (UPS) and lower limbs (LLS) during gait after the application of magnetic stimulation. Further studies should be attempted to investigate the different frequencies and intensities of magnetic stimulation to treat many different disabilities in different neurological diseases.

\section{References}

[1] Marr, J.A. (1991) The Experience of Living with Parkinson’s Disease. Journal for Neuroscience, 23, 325-329.

[2] Muskens, L. (1992) The Central Connection of the Vestibular Nuclei with Corpus Striatum and Their Significance for Ocular Movements and for Locomotion. Brain, 30, 1129-1135.

[3] Mitchell, I.J., Boyce, S. and Sambrook, M.A. (1992) A-2-Deoxyglucose Study of the Effects of Dopamine Agonists on the Parkinson's Primate Brain. Brain, 115, 809-815. http://dx.doi.org/10.1093/brain/115.3.809

[4] Almeida, Q.J., Wishart, L.R. and Lee, T.D. (2005) Disruptive Influence of a Cued Voluntary Shift on Coordinated Movement in Parkinson's Disease. Neuropsychologia, 41, 442-452. http://dx.doi.org/10.1016/S0028-3932(02)00155-0

[5] Baron, M.S., Vitek, J.L., Bakay, R.A., Green, J., Kaneoke, Y. and Hashimoto, T. (2004) Treatment of Advanced Parkinson's Disease by Posterior GPi Pallidotomy: 1-Year Results of a Pilot Study. Annals of Neurology, 40, 355-366. http://dx.doi.org/10.1002/ana.410400305

[6] Bonuccelli, U. and Del Dotto, P. (2006) New Pharmacologic Horizons in the Treatment of Parkinson’s Disease. Neurology, 7, 30-38. http://dx.doi.org/10.1212/WNL.67.7_suppl_2.S30

[7] Brooks, D.J., Playford, E.D. and Ibanez, V. (2004) Isolated Tremor and Disruption of the Nigrostriatal Dopaminergic System: A Fluorine-18-Dopa Study. Journal of Neurology, 42, 1554-1560.

[8] Giladi, N., Treves, T.A., Simon, E.S. and Shabtai, H. (2004) Gait Festination in Parkinson’s Disease. Parkinsonism \& Related Disorders, 7, 135-138. http://dx.doi.org/10.1016/S1353-8020(00)00030-4

[9] Flament, D., Vaillancourt, D.E., Kempf, T., Shannon, K. and Corcos, D.M. (2005) EMG Remains Fractionated in Parkinson's Disease, despite Practice-Related Improvements in Performance. Clinical Neurophysiology, 119, 2385-2396.

[10] Roy, S. and Oddsson, L. (1998) Classification of Paraspinal Muscle Impairment by Surface Electromyography. Journal of Physical Therapy, 78, 838-851.

[11] Globe, L.I. and Davis, P.H. (1998) Progressive Supranclear Palsy. Recent Advances. In: Jankovic, J. and Tolosa, T., Eds., Parkinson's Disease and Movement Disorders, Urban and Schwarzenber, Baltimore, 121-130.

[12] Jellinger, K., Riederer, P. and Tomonga, M. (2003) Progressive Supranuclear Palsy: Clinical Pathological and Biochemical Studies. Journal of Neural Transmission, 16, 111-128.

[13] Kanazawa, I. (1996) Clinical Pathophysiology of Basal Ganglia Disease. In: Vinken, P.J., Bruyn, G.W. and Klawans, H.L., Eds., Handbook of Clinical Neurology: Extrapyramidal Disorders, Chapter 5, Elsevier, Amsterdam, 65-85.

[14] Kienzl, E., Riderer, P., Jellinger, K. and Wesemann, W. (2004) Transitional States of Central Serotonin Receptors in Parkinson's Disease. Journal of Neural Transmission, 51, 113-122. http://dx.doi.org/10.1007/BF01664009

[15] Lees, A.J. (1997) Progressive Supranuclear Palsy. In: Marsden, C.D. and Fahn, S., Eds., Movement Disorders, Butterworth, London, 272-289. 
[16] Marsden, C.D. and Parkes, J.D. (2003) “On and Off” Variability and Response Swings in Parkinson’s Disease. Ptiman Medical, Kent, 265-274.

[17] Mestre, D., Blin, O. and Serratrice, G. (2004) Contrast Sensitivity Is Increased in a Case of Non-Parkinsonian Freezing Gait. Neurology, 42, 189-194. http://dx.doi.org/10.1212/WNL.42.1.189

[18] Masur, H., Erim, Y., Oberwittler, C. and Hornung, W.P. (2003) Post Excitatory Inhibition after Transcranial Magnetic Stimulation of the Motor Cortex in Patients with Drug-Induced Parkinsonism and in Healthy Individuals. International Clinical Psychopharmacology, 13, 79-82. http://dx.doi.org/10.1097/00004850-199803000-00004

[19] Nagasaki, H., Kosaka, K. and Nakamura, R. (2003) Distribution of Rhythm Formation in Patients with Hemispheric Lesion. Journal of Experimental Medicine, 135, 231-236.

[20] Pohl, P., Duncan, P., Perera, S., long, J., Liu, W., Zhou, J. and Kautz, S. (2002) Rate of Isometric Knee Extension Strength Development and Walking Speed after Stroke. Journal of Rehabilitation Research and Development, 39, 651-657.

[21] Beckley, D.J., Bloem, B.R., Van Dijk, J.G., Roos, R.A. and Remler, M.P. (2002) Electrophysiological Correlates of Postural Instability in Parkinson’s Disease. Electroencephalography and Clinical Neurophysiology, 81, 263-268. http://dx.doi.org/10.1016/0168-5597(91)90012-M

[22] Agostino, R., Berardelli, A., Formica, A., Accornero, N. and Manfredi, M. (1992) Sequential Arm Movements in Patients with Parkinson's Disease, Huntington's Disease and Dystonia. Brain, 115, 11481-1495. http://dx.doi.org/10.1093/brain/115.5.1481

[23] Bloem, B.R., Beckley, D.J., Van Dijk, J.G., Zwinderman, A.H., Remler, M.P. and Roos, R.A. (2003) Influence of Dopaminergic Medication on Automatic Postural Responses and Balance Impairment in Parkinson's Disease. Movement Disorders, 11, 509-521. http://dx.doi.org/10.1002/mds.870110506

[24] Andrews, C. (2005) Influence of Dystonia on the Response to Long Term L-Dopa Therapy in Parkinson’s Disease. Journal of Neurology, Neurosurgery, and Psychiatry, 36, 630-636. http://dx.doi.org/10.1136/jnnp.36.4.630

[25] Gruber, R.A., Marinus, A. and Visser, M. (2002) Inter and Intra-Rater Reliability and Discriminative Ability of Five Measures of Bradykinesia in Subjects with and without Parkinson's Disease. Movement Disorders, 17, 19-25.

[26] Wills, A.J, Jenkins, I.H., Thompson, P.D., Frackowiak, R.S.J., Findley, L.J. and Brooks, D.J. (2004) Red Nuclear and Cerebellar but Not Olivary Activation Associated with Essential Tremor: A Positron Emission Tomography Study. Annals of Neurology, 36, 636-642. http://dx.doi.org/10.1002/ana.410360413

[27] Abbruzzese, G., Vische, M., Ratto, S. and Favole, E. (1985) Assessment of Motor Neuron Excitability in Parkinsonian Rigidity by the F Wave. Journal of Neurology, 232, 246-249. http://dx.doi.org/10.1007/BF00313788

[28] Fahn, S. (2005) The Freezing Phenomenon in Parkinsonism. Advances in Neurology, 67, 53-63.

[29] Colebatch, J.G., Findley, L.J. and Frackowiak, R.S.J. (2001) Preliminary Report: Activation of the Cerebellum in Essential Tremor. Lancet, 336, 1028-1030. http://dx.doi.org/10.1016/0140-6736(90)92489-5

[30] Kozel, F.A., George, M.S. and Simpson, K.N. (2004) Decision Analysis of the Cost-Effectiveness of Repetitive Transcranial Magnetic Stimulation versus Electroconvulsive Therapy for Treatment of Nonpsychotic Severe Depression. CNS Spectrums, 9, 476-482.

[31] Tarsy, D. (2002) Neuroleptic Induced Movement Disorders. In: Quinn, N.P. and Jenner, P.G., Eds., Disorders of Movement, Academic Press, London, 361-393.

[32] Robertson, C. and Flowers, K.A. (1990) Motor Set in Parkinson’s Disease. Journal of Neurology, Neurosurgery, and Psychiatry, 53, 583-590. http://dx.doi.org/10.1136/jnnp.53.7.583

[33] Uozumi, T., Tsuji, S. and Murai, Y. (2000) Motor Potentials Evoked by Magnetic Stimulation of the Motor Cortex in Normal Subjects and Patients with Motor Disorders. Electroencephalography and Clinical Neurophysiology, 81, 251256. http://dx.doi.org/10.1016/0168-5597(91)90010-U

[34] Rajput, A.H. (2004) Clinical Features of Tremor in Extrapyramidal Syndromes. In: Friendly, L.J. and Kaller, W.C., Eds., Handbook of Tremor Disorder, Chapter 9, Marcel Dekker, New York, 275-292.

[35] Rabey, I.M., Kelin, C. and Molo, C.A. (2002) Comparison of the Unified Parkinson's Disease Rating Scale and the Short Parkinson's Evaluation Scale in Patients with Parkinson's Disease after Levodopa Loading. Clinical Neuropharmacology, 25, 83-88. http://dx.doi.org/10.1097/00002826-200203000-00005

[36] Scott, R., Hines, N., Carroll, C., Hyman, N. and Panasstasiou, V. (2004) Neuropsychological, Neurological and Functional Outcome Following Pallidotomy for Parkinson's Disease. A Consecutive Series of Eight Simultaneous Bilateral and Twelve Unilateral Procedures. Brain, 121, 659-675. http://dx.doi.org/10.1093/brain/121.4.659

[37] Serra, G., Collu, M. and Gessa, G.L. (2001) Dopamine Receptors Mediating Yawning: Are They Autoreceptors. European Journal of Pharmacology, 120, 187-192. http://dx.doi.org/10.1016/0014-2999(86)90539-X 
[38] Burton, S., Daya, S. and Potgieter, B. (2001) Melatonin Modulates Apomorphine Induced Rotational Behavior. Experiential, 47, 466-469. http://dx.doi.org/10.1007/BF01959946

[39] Merello, M., Balej, J., Delfino, M., Cammarota, A., Betti, O. and Leiguarda, R. (2002) Apomorphine Induces Changes in GPi Spontaneous Outflow in Patients with Parkinson's Disease. Movement Disorders, 14, 44-45.

[40] Manev, J., Kharlamov, A. and Joo, J.Y. (2004) Increased Brain Damage after Stroke or Excitotoxic Seizures in Melatonin-Deficient Rats. FASEB Journal, 10, 1546-1551.

[41] Reiter, R.J. (1993) Static and Extremely Low Frequency Electromagnetic Filed Exposure: Reported Effects on the Circadian Production of Melatonin. Journal of Cellular Biochemistry, 51, 394-403.

[42] Antolín, L., Rodríguez, C., Saínz, R.M., Mayo, J.C., Uría, H., Kotler, M.L., Rodríguez-Colunga, M.J., Tolivia, D. and Menéndez-Peláez, A. (1996) Neurohormone Melatonin Prevents Cell Damage: Effect on Gene Expression for Antioxidant Enzymes. FASEB Journal, 10, 882-890.

[43] Dietz, V., Zilstra, W., Prokop, T. and Berger, W. (2004) Leg Muscle Activation during Gait in Parkinson's Disease; Adaptation and Interlinks Coordination. Electroencephalography and Clinical Neurophysiology, 92, 408-415.

[44] Bliss, V.L. and Heppner, F.H. (2005) Circadian Activity Rhythms Influenced by Near Zero Magnetic Field. Nature, 261, 411-412. http://dx.doi.org/10.1038/261411a0

[45] Storey, E. and Beal, M.F. (2005) Neurochemical Substrate of Rigidity and Chorea in Huntington's Disease. Brain, 116, 1201-1222. http://dx.doi.org/10.1093/brain/116.5.1201

[46] Bell, G., Marino, A., Chesson, A. and Struve, F. (2000) Electrical States in the Rabbit Brain Can Be Altered by Light and Electromagnetic Fields. Brain Research, 57, 307-315.

[47] Chen, R., Classen, J., Gerloff, C., Celnnik, P., Wassermann, E.M., Hallett, M. and Cohen, L.G. (1997) Depression of Motor Cortex Excitability by Low Frequency Transcranial Magnetic Stimulation. Journal of Neurology, 48, 13981403.

[48] Poirier, L.J., Sourkes, T.L., Bouvier, G., Boucher, R. and Carabin, S. (2000) Striatal Amines Experimental Tremor and the Effect of Harmaline in the Monkey. Brain, 89, 37-52. http://dx.doi.org/10.1093/brain/89.1.37

[49] Finsterer, J., Muellisacher, W. and Mamoli, B. (2005) Yes/Yes Head Tremor without Appendicular Tremor after Bilateral Cerebellar Infarction. Journal of the Neurological Sciences, 139, 242-245. http://dx.doi.org/10.1016/0022-510X(96)00153-0

[50] Davis, J. (1997) Team Management of Parkinson's Disease. American Journal of Occupational Therapy, 31, $300-315$.

[51] Fall, P.A., Ekman, R., Granerus, A.K., Thorell, L.H. and Walinder, J. (2003) ECT in Parkinson’s Disease. Changes in Motor Symptoms, Monoamine Metabolites and Neuropeptides. Journal of Neural Transmission, 10, 129-140. http://dx.doi.org/10.1007/BF02251228

[52] Blackman, C.F., Benane, S.G., Kinney, L.S., House, D.E. and Joines, W.T. (2004) Effect of ELF Fields on Calciumion Efflux from Brain Tissue in Vitro. Radiation Research, 92, 510-520. http://dx.doi.org/10.2307/3575923

[53] Shimamoto, H., Takasaki, K., Shigemori, M., Imaizumi, T., Ayabe, M. and Shoji, H. (2005) Therapeutic Effect and Mechanism of Repetitive Transcranial Magnetic Stimulation in Parkinson's Disease. Journal of Neurology, 248, 48-52. http://dx.doi.org/10.1007/PL00007826

[54] Touge, T., Nishiyama, Y. and Takeuchi, H. (2005) Effects of Successive Repetitive Transcranial Magnetic Stimulations on Motor Performance and Brain Perfusion in Idiopathic Parkinson's Disease. Journal of the Neurological Sciences, 15, 41-46.

[55] Guekht, A., Selikhova, M., Serkin, G. and Gusev, E. (2005) Implementation of the TMS in the Early Stages of Parkinson's Disease. Electromyography and Clinical Neurophysiology, 45, 291-297.

[56] Behrman, S., Carroll, I.D. and Janota, I. (2005) Progressive Supranuclear Palsy. Clinico-Pathological Study for Four Cases. Brain, 92, 663-678. http://dx.doi.org/10.1093/brain/92.3.663

[57] Sandyk, R. (2003) Treatment with AC Pulsed Electromagnetic Fields Improves the Response to Levodopa in Parkinson's Disease. International Journal of Neuroscience, 9, 30-35.

[58] Weiner, W.J., Lang, A.E. and Davis, P.H. (2004) Movement Disorders. A Comprehensive Survey. Future, Mount Kisco, 147-161.

[59] Bogey, R. (2004) Gait Analysis. Journal of Medical, 27, 1-13.

[60] Martin, J.P. (2004) The Basal Ganglia and Posture. Chapter 11, Pitman Medical, London, 49-51.

[61] Marinus, J., Visser, M., Stiggelbout, A.M., Martin, A.M., Mrtinez, P., Bonucelli, U. and Van, J. (2005) A Scale for the Assessment of Motor Impairments and Disabilities in Parkinson's Disease: The SPES/SCOPA. Journal of Neurology, Neurosurgery, and Psychiatry, 75, 388-395. http://dx.doi.org/10.1136/jnnp.2003.017509

[62] Floyd, W.F., Sliver, P.H. and Long, A.E. (2002) The Function of the Erector Spinae Muscles in Certain Movements 
and Postures in Man. The Journal of Physiology, 129, 184-203.

[63] Brannan, T., Martinez-Tica, J. and Yahr, M.D. (2003) Effect of Repeated Electroconvulsive Shock on Striatal L-Dopa and Dopamine Metabolism: An in Vivo Study. Journal of Neural Transmission, 6, 35-44. http://dx.doi.org/10.1007/BF02252621

[64] Aldegunde, M., Miguez, I. and Veria, J. (2005) Effects of Pinealectomy on Regional Brain Serotonin Metabolism. International Journal of Neuroscience, 26, 9-13.

[65] Kellner, C.H., Beale, M.D., Prichett, J.T., Bernstein, H.J. and Burns, C.M. (2001) Electroconvulsive Therapy and Parkinson's Disease: The Case for Further Study. Psychopharmacology Bulletin, 30, 495-500.

[66] Smith, A.D. and Bolam, J.P. (2005) The Neural Network of the Basal Ganglia as Revealed by the Study of Synaptic Connections of Identified Neurons. Trends in Neurosciences, 23, 13-25. 